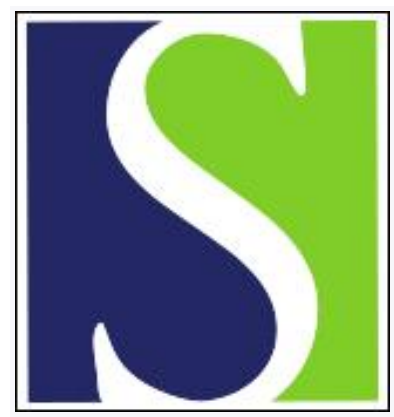

Scand J Work Environ Health 2016;42(2):125-134

https://doi.org/10.5271/sjweh.3549

Published online: 01 Feb 2016, Issue date: 01 Mar 2016

Social support modifies association between forward bending of the trunk and low-back pain: Cross-sectional field study of blue-collar workers

by Villumsen M, Holtermann A, Samani A, Madeleine P, Jørgensen MB

Workers experiencing low social support at work have three times higher likelihood of having low-back pain when performing long duration of forward bending compared with workers with short duration of forward bending. Practitioners should be aware of social support for alleviating low-back pain.

Affiliation: Physical Activity and Human Performance group, SMI, Department of Health Science and Technology, Aalborg University, Aalborg, Fredrik Bajers Vej 7, DK-9220 Aalborg, Denmark. mvi@hst.aau.dk

Refers to the following texts of the Journal: 2015;41(1):65-74

2014;40(3):252-265 2013;39(2):164-169 2011;37(1):6-29

1991;17(2):81-90 1993;19(5):297-312 2004;30(4):261-278

1997;23(4):243-256

The following articles refer to this text: 2018;44(1):47-57; 2018;44(5):530-538; 2020;46(4):373-381

Key terms: accelerometry; back pain; bending of the trunk; blue-collar worker; body posture; cross-sectional study; diurnal measurement; forward bending; inclination; low-back pain; musculoskeletal disorder; occupational physical activity; pain; physical activity; physical demand; risk assessment; social support; workload

This article in PubMed: www.ncbi.nlm.nih.gov/pubmed/26828769

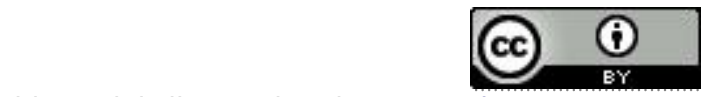




\title{
Social support modifies association between forward bending of the trunk and low-back pain: Cross-sectional field study of blue-collar workers
}

\author{
Morten Villumsen, MSc, ${ }^{1,2}$ Andreas Holtermann, PhD, ${ }^{2,3}$ Afshin Samani, PhD, ${ }^{1}$ Pascal Madeleine, DSc, ${ }^{1}$ \\ Marie Birk Jørgensen, $P h D^{2}$
}

\begin{abstract}
Villumsen M, Holtermann A, Samani A, Madeleine P, Jørgensen MB. Social support modifies association between forward bending of the trunk and low-back pain: Cross-sectional field study of blue-collar workers. Scand J Work Environ Health. 2016;42(2):125-134. doi:10.5271/sjweh.3549
\end{abstract}

Objectives This study aimed to investigate the association between forward bending of the trunk and lowback pain intensity (LBPi) among blue-collar workers in Denmark as well as whether the level of social support modifies the association.

Methods In total, 457 workers were included in the study. The forward bending of $\geq 30^{\circ}$ was computed from accelerometer recordings for several consecutive days during work, categorized into long (highest tertile) and short-moderate (remaining tertiles) duration. LBPi was measured on a $0-10$ scale and categorized into low $(\leq 5)$ and high $(>5)$ pain. Self-reported social support was categorized into low, moderate, and high levels. Multi-adjusted logistic regressions estimated the association between forward bending and LBPi and the effect modification by social support.

Results Forward bending and LBPi were not significantly associated but modified by social support. Workers with low social support and long duration of forward bending had higher likelihood of high LBPi [odds ratio (OR) 2.97, 95\% confidence interval (95\% CI) 1.11-7.95] compared to workers with high social support and long duration of forward bending. Among workers with low social support, workers with long duration of forward bending had higher likelihood of high LBPi (OR 3.28, 95\% CI 0.99-10.90) compared to workers with shortmoderate duration of forward bending. Among workers with high social support, workers with long duration of forward bending had reduced likelihood of high LBPi (OR 0.39, 95\% CI 0.16-0.95) compared to workers with short-moderate duration of forward bending.

Conclusions Social support modifies the association between objectively measured forward bending and LBPi among blue-collar workers.

Key terms accelerometry; body posture; diurnal measurement; inclination; musculoskeletal disorder; occupational physical activity; physical activity; physical demand; risk assessment; workload.

Low-back pain (LBP) is a major global health problem (1) with a lifetime prevalence in developed countries of $75-84 \%$ (2). Furthermore, LBP in the working population constitutes a major cause of absenteeism in Western countries $(3,4)$ with serious implications for the individual, workplaces, and society $(2,5,6)$. The origin of back pain is multifactorial (7), but LBP is a very important estimate of sickness absence (8), indicating that the individual worker's perception of pain is an important element with respect to the consequence for sickness absence, regardless of the underlying pathology. LBP has also been shown to be occupationally related and therefore substantial efforts have been made to identify risk factors for LBP, particularly among blue-collars workers $(9,10)$ where the risk of sickness absence from LBP is higher (8).

One of the suggested significant work-related risk factors for LBP is forward bending of the trunk (11), and

1 Physical Activity and Human Performance group, SMI, Department of Health Science and Technology, Aalborg University, Aalborg, Denmark.

2 The National Research Centre for the Working Environment, Copenhagen, Denmark.

3 Institute of Sports Science and Clinical Biomechanics, Physical Activity and Health in Work Life, Department of Sports Science and Clinical Biomechanics, University of Southern Denmark, Odense, Denmark.

Correspondence to: Morten Villumsen, Physical Activity and Human Performance group, SMI, Department of Health Science and Technology, Aalborg University, Aalborg, Fredrik Bajers Vej 7, DK-9220 Aalborg, Denmark. [Email: mvi@hst.aau.dk] 
Murtezani et al (8) found trunk flexion among production workers to be one of the main risk factors for sickness absence due to LBP. Forward bending introduces cumulative doses of biomechanical loading of the spine and back muscles, which may induce wear and tear on the muscles and ligaments, leading to LBP (12-14). However, studies on the association between forward bending of the trunk and LBP show conflicting results (11). One reason for the conflicting results can be differences in methodology used to measure forward bending of the trunk (15). The majority of studies investigating the association between forward bending of the trunk and LBP (11) have been criticized for using self-reported measures $(16,17)$ or the short window of observations (18-21). Therefore, valid objective measurements using accelerometers are preferable due to higher precision (22) and possibility for longer measurement periods (23).

We recently reported that blue-collar workers with long duration of objectively measured forward bending of the trunk did not have higher likelihood of high LBP intensity (LBPi) compared to workers with short-moderate duration of forward bending among 198 blue-collar workers in Denmark (23). On the contrary, we observed that workers having short-moderate duration of forward bending had tendencies towards increased likelihood of high LBPi compared to workers with long duration of forward bending during work. The reasoning for this observed tendency could be: (i) workers with high LBPi are likely to eschew forward bending due to discomfort or pain, representing fear avoidance behavior $(24,25)$; (ii) workplaces or work teams may adjust the strenuous work tasks based on LBPi of the worker (26); or (iii) the healthy worker effect, increasing the risk of workers with a combination of a work implying long duration of forward bending and high LBPi to withdraw from the labor market (23).

With respect to reasoning (ii), high social support from colleagues and management has been shown to be an important aspect in relation to work-related health (27). In Denmark, a rather comprehensive focus on working conditions makes it plausible that social support for workers influences the allocation of strenuous work task among the workers. If that is the case, the worker's ability to influence how forward bending of the trunk is performed may be lower among workers with low social support compared to those with high social support, irrespective of the total duration of forward bending. In this study, we therefore hypothesized that social support would modify the association between forward bending of the trunk and LBPi $(23,28)$, see figure 1 .

The aims of this study were to investigate the association between forward bending of the trunk and LBPi among blue-collar workers in Denmark, and assess whether the level of social support modifies the association between forward bending of the trunk and LBPi.

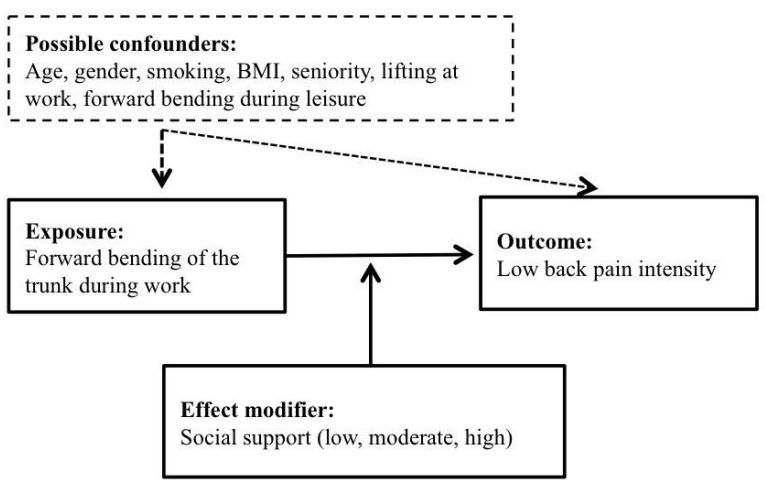

Figure 1. Illustration of the hypothesis that social support modifies the association between forward bending of the trunk during work and low-back pain intensity. [BMI=body mass index.]

\section{Methods}

\section{Study population and protocol}

This study is based on baseline data from the field study called Danish Physical Activity Cohort with Objective Measurements (DPhacto) (29). For demographic information of the study population, see tables 1,2 and 3. All companies gave consent for their employees to participate during working time. All workers from the included companies were given information of the aim, form, and content of the study at a pre-information meeting and invited to participate in the study voluntarily. Workers willing to participate gave their signed informed consent to measurements of anthropometric and objective diurnal measurements using accelerometers as well as completion of a questionnaire (see below). All bluecollar workers aged 18-65 were eligible for inclusion. Criteria of exclusion were plaster allergy, fever, or pregnancy. Workers with status as trainees, apprentices or canteen employees were also excluded. An overview of the flow of participants is shown in figure 2.

Data collection was conducted from December 2011 to March 2013. The Danish Data Protection Agency has accepted the handling and storage of data (29). The local Ethics Committee (H-2-2012-011) approved the study, which was conducted in accordance with the Declaration of Helsinki. The reporting of the study follows the Strengthening the Reporting of Observational studies in Epidemiology (STROBE statement) (30).

\section{Objective measurements of types of physical activity and body positions}

For measures of upper- and lower-body positions and movements, two tri-axial accelerometers (ActiGraph GT3X+, ActiGraph LLC, Pensacola, FL, USA) were mounted with the $\mathrm{x}$-axis pointing downwards and $\mathrm{y}$-axis 
and z-axis horizontally (31). The accelerometers are small, wireless, light-weighted (19 grams) and enable unobstructive recording of daily activities. The accelerometers were placed at the processus spinosus at the level of T1-T2 and at the halfway mark on the vertical line between spina illiaca anterior superior and the patella (31). If the workers experienced itching influencing their sleep, discomfort, or felt the accelerometers were interfering with their work, they were instructed to remove them. The workers filled in a diary incorporating information about working hours, leisure hours, sleep, non-wear time and specific time for the reference measurements (ie, upright stance for 15 seconds while standing still in neutral position). A Matlab-based program Acti4 (National Research Centre for the Working Environment, Copenhagen, Denmark and Federal Institute for Occupational Safety and Health, Berlin, Germany) was used to determine when the worker was standing still or moving slightly defined as a standing position, including small movement, without regular walking $(23,31)$.

Within the included study population, all recordings during non-working days, bedtime or sleep intervals and non-wear periods for each individual were excluded from the analysis. Non-wear periods were defined: (i) as periods of $>60$ minutes without any detected accelerations, (ii) as non-wear periods reported by the participant, and (iii) by visual inspection of the accelerometer data (28). We scrutinized the observed data into activities during working and leisure time. We included days with (i) $\geq 4$ hours of recordings of working time or $\geq 75 \%$ of average self-reported working time, and (ii) $\geq 4$ hours measured during leisure time or $\geq 75 \%$ of average selfreported leisure time per day if the worker had $\geq 2$ days of recordings. Workers with only one day of recording were included if this comprised (i) $\geq 4$ hours of recordings of working time and $\geq 75 \%$ of average self-reported working time, and (ii) $\geq 4$ hours measured during leisure time and $\geq 75 \%$ of average self-reported leisure time during that specific day. This resulted in a population with objective measurements of $\mathrm{N}=657$.

\section{Forward bending of the trunk while standing still or moving slightly}

Using the individual reference measurements obtained at the beginning of the recordings, the duration (minutes/day) of forward bending in the frontal and sagittal planes was computed with a cut-point of $\geq 30^{\circ}$ from the individual reference point $(23,32)$. This cut-point was protocol-based on a previous study where different cutpoints on the association between forward bending and LBPi were tested (23). Forward bending was divided into two categories representing long (upper tertile of the population with objective measurements) and short-

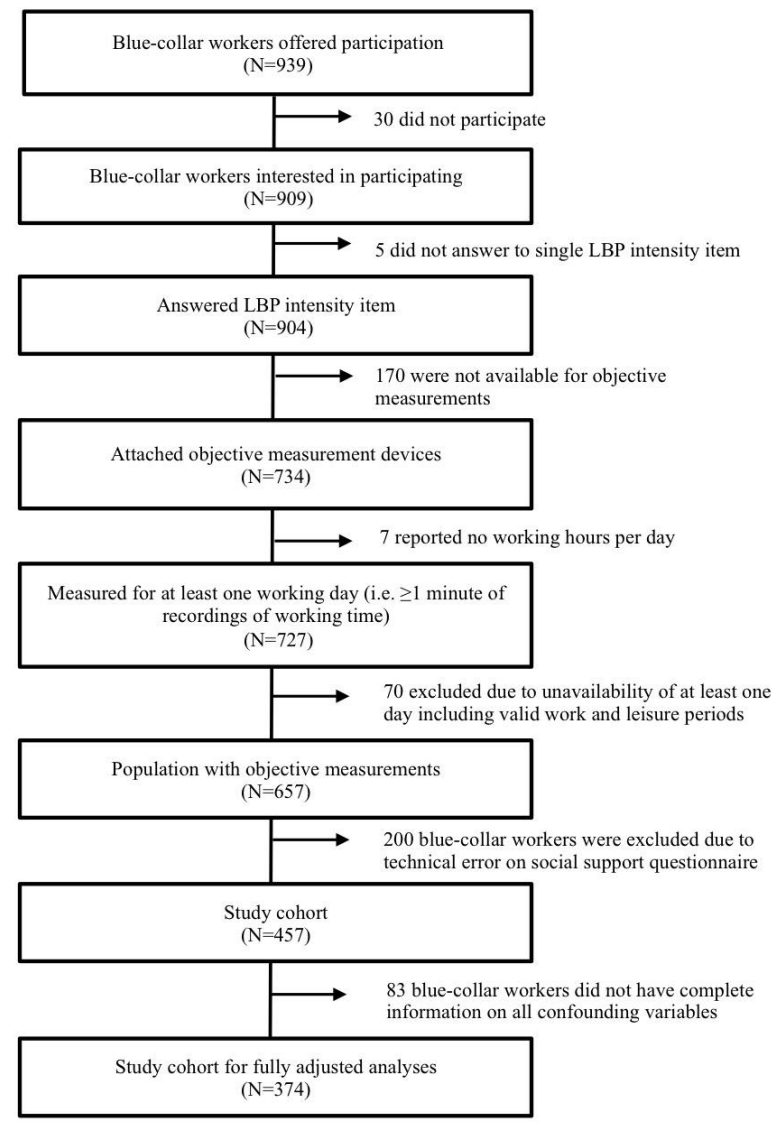

Figure 2. Flow chart containing information about study procedure, participation, inclusion, and exclusion criteria for the study population.

moderate (remaining tertiles of the population with objective measurements) duration of forward bending (23). Working time was comprised of the time spent at work; leisure time was comprised of the remaining time during the working day, except when the workers were in bed at night. In all statistical analyses, only forward bending while standing or moving slightly was included to avoid including forward bending while sitting or lying.

\section{Low-back pain intensity}

The workers were asked to rate the worst intensity of LBP during the last three months on a numeric rating scale from 0-10 anchored with 0: 'no pain' and 10: 'worst imaginable pain' (33). The LBPi was then divided into two categories representing low $(\leq 5)$ and high $(>5)$ LBPi in line with previous studies $(23,34)$. An additional categorization with no LBP (score 0) and LBP (score 1-10) was also performed.

\section{Potential confounders}

The potential confounders in this study included indi- 
vidual risk factors: age, gender, smoking habits, and body mass index (BMI) (35-37) as well as work-related risk factors: social support as explained below (38-41) and seniority in addition to lift burden at work (42). Moreover, forward bending of the trunk during work was adjusted for forward bending during leisure. Age and gender were obtained and crosschecked with the questionnaire. Seniority at the job and smoking habits were obtained through the questionnaire. The BMI was calculated using weight and height. The lift burden at work was established using an inquiry about the typical weight lifted at work $(\mathrm{kg})$ times the duration of lifting the burden (minutes). The typical lift burden was selfreported through the question "During your workday, what is the magnitude of the mass you typically are carrying/lifting? ( $\geq 1 \mathrm{~kg}$ and $\geq 5$ minutes/day)?" and then verified using dumbbells $(1-5-10-15-30 \mathrm{~kg})$. The self-reported time with lifting during a workday was also determined through the question "Total time spent carrying/lifting this weight on a typical working day (minutes/day)?" The lift burden variable was then stratified using a median split of the population with objective measurements.

\section{Social support at work}

Social support at work in general covers two items: social support among colleagues and from supervisors to employees (43), shown to be of importance for workrelated health, satisfaction, and sick leave (27). In this study we used the Torp et al (27) approach, addressing social support at work through two questions: "Is there a good cooperation between the management and the employees?" and "Is there good cooperation between the colleagues at work?" $(43,44)$. Social support was then coded into a scale ranged from $0-100$, with 100 representing the highest degree of social support (45). The social support scale was subsequently categorized into tertiles indicating low, moderate, and high social support. Concerning the questionnaire on social support, data were not collected in the last three companies and therefore handled as data not missing at random. The final study population for the current study was thus 457 blue-collar workers, see figure 2 .

\section{Statistical analysis}

The statistical analyses were conducted in accordance with our earlier study (23), where short-moderate and long duration of forward bending during work was regressed on low and high LBPi using binary logistic regressions in a crude model as well as in a fully adjusted model with forced entry of covariates (ie, age, gender, seniority, BMI, smoking, the lift burden at work, social support and, forward bending during leisure time). Further, additional similar analyses with a categorization of no LBP (score 0) and LBP (score $1-10$ ) were performed. To investigate if social support was associated with the duration of forward bending and LBPi, both Pearson's Chi test on dichotomized variables and one-way analyses of variance with the continuous variables were conducted. Further, sensitivity analyses were performed to test the robustness of the main analyses: lower (ie, $\leq 4$ on the $0-10$ scale) and higher (ie, $\leq 6$ on the $0-10$ scale) cut-points for LBPi, as well as using percentage of time spent forward bending during work.

\section{Effect modification by social support}

The recommendations for analyzing and presenting effect modification by Knol and VanderWeele (46) were followed to explore whether social support modified the association between forward bending and LBPi. Binary logistic regressions with forced entry of covariates were performed for all six combined groups of forward bending and social support (ie, two categories of forward bending $\times$ three categories of social support) on LBPi. Moreover, odds ratios (OR) between forward bending and LBPi within each stratum of social support were analyzed. Finally, we tested for the interaction effect between forward bending and social support on LBPi. Further analyses for the effect modification were performed with an additional categorization of LBPi of no LBP (score 0) and LBP (score 1-10).

OR are presented with $95 \%$ confidence intervals ( $95 \%$ CI). Statistical significance was considered at $\mathrm{P} \leq 0.05$. All statistical analyses were conducted using the Statistical Package for the Social Sciences (IBM Corporation SPSS statistics, Version 22.0, Armonk, NY, USA).

\section{Results}

On working days, the total measured hours of working time used for the main analyses was 8932 and 10374 hours for work and leisure time, respectively. For work and leisure, the average recorded hours with accelerometer measurements was 19.6 [standard deviation (SD) 8.2] hours and 22.7 (SD 8.8) hours per worker, respectively. The accelerometers were on average worn for 2.6 (SD 1.0) working days. Fifty-four percent of the workers wore the accelerometers for $\geq 3$ consecutive days (tables 1 and 2). Of the total population of workers, the cleaning sector represented $28 \%$, manufacturing $59 \%$ and transportation $13 \%$. In the male population, $68 \%$ worked in manufacturing, $25 \%$ in transportation, and $7 \%$ in the cleaning sector. Similarly, $50 \%$ of females were employed in manufacturing, $49 \%$ in cleaning, and $1 \%$ in transportation. The mean BMI was 27.5 (SD 4.9) 
Table 1. Descriptive characteristics of the blue-collar workers stratified by low-back pain (LBP) intensity.

\begin{tabular}{|c|c|c|c|c|c|c|}
\hline \multirow[t]{3}{*}{ Variables } & \multicolumn{6}{|c|}{ LBP intensity } \\
\hline & \multicolumn{3}{|c|}{$\operatorname{Low}(\leq 5)$} & \multicolumn{3}{|c|}{ High (>5) } \\
\hline & $\mathrm{N}$ & Mean & SD & $\mathrm{N} \mathrm{I}$ & Mean & SD \\
\hline Population & 334 & & & 123 & & \\
\hline LBP intensity $(0-10)$ & 334 & 1.7 & 1.9 & 123 & 7.7 & 1.2 \\
\hline Frequency (no LBP, score 0) & 146 & & & 0 & & \\
\hline \multicolumn{7}{|l|}{ Gender } \\
\hline Male & 165 & & & 60 & & \\
\hline Female & 169 & & & 63 & & \\
\hline Age (years) & 334 & 45.7 & 8.9 & 123 & 46.7 & 9.4 \\
\hline Smokers & $100^{a}$ & & & $36^{b}$ & & \\
\hline Seniority (months) & 315 & 141 & 111 & 113 & 161 & 130 \\
\hline BMI $\left(\mathrm{kg} / \mathrm{m}^{2}\right)$ & 328 & 27.3 & 5.1 & 122 & 27.9 & 4.6 \\
\hline \multicolumn{7}{|l|}{$\begin{array}{l}\text { Duration category of forward } \\
\text { bending of the trunk of } \geq 30^{\circ}\end{array}$} \\
\hline \multicolumn{7}{|l|}{ Work } \\
\hline Short-moderate & 226 & & & 89 & & \\
\hline Long & 108 & & & 34 & & \\
\hline \multicolumn{7}{|l|}{ Leisure } \\
\hline Short-moderate & 217 & & & 77 & & \\
\hline Long & 117 & & & 46 & & \\
\hline \multicolumn{7}{|l|}{ Lift burden at work } \\
\hline Low & 167 & & & 66 & & \\
\hline High & 133 & & & 45 & & \\
\hline \multicolumn{7}{|l|}{ Social Support } \\
\hline Low & 79 & & & 33 & & \\
\hline Moderate & 118 & & & 39 & & \\
\hline High & 137 & & & 51 & & \\
\hline
\end{tabular}

a 100 out of 323 blue-collar workers.

b 36 out of 116 blue-collar workers.

Table 2. Descriptive characteristics of the blue-collar workers stratified by the level of social support. [LBP=low-back pain.]

\begin{tabular}{|c|c|c|c|c|c|c|c|c|}
\hline \multirow[t]{3}{*}{ Variables } & \multicolumn{8}{|c|}{ Level of social support } \\
\hline & \multicolumn{3}{|c|}{ Low } & \multicolumn{2}{|c|}{ Moderate } & \multicolumn{3}{|c|}{ High } \\
\hline & $\mathrm{N}$ & Mean & SD & $\mathrm{N}$ & Mean SD & $\mathrm{N}$ & Mean & SD \\
\hline Population & 112 & & & 157 & & 188 & & \\
\hline LBP intensity $(0-10)$ & 112 & 3.5 & 3.1 & 157 & 3.43 .1 & 188 & 3.2 & 3.3 \\
\hline $\operatorname{Low}(\leq 5)$ & 79 & & & 118 & & 137 & & \\
\hline $\operatorname{High}(>5)$ & 33 & & & 39 & & 51 & & \\
\hline \multicolumn{9}{|l|}{ Gender } \\
\hline Male & 56 & & & 81 & & 88 & & \\
\hline Female & 56 & & & 76 & & 100 & & \\
\hline Age (years) & 112 & 45.7 & 9.4 & 157 & 45.08 .6 & 188 & 47.0 & 9.0 \\
\hline Smokers & $39^{a}$ & & & $44^{b}$ & & $53^{e}$ & & \\
\hline Seniority (months) & 105 & 137 & 103 & 146 & 150112 & 177 & 149 & 127 \\
\hline BMI $\left(\mathrm{kg} / \mathrm{m}^{2}\right)$ & 111 & 27.2 & 4.9 & 155 & $27.5 \quad 5.2$ & 184 & 27.6 & 4.7 \\
\hline \multicolumn{9}{|l|}{$\begin{array}{l}\text { Duration category of } \\
\text { forward bending of } \\
\text { the trunk of } \geq 30^{\circ}\end{array}$} \\
\hline \multicolumn{9}{|l|}{ Work } \\
\hline Short-moderate & 70 & & & 121 & & 124 & & \\
\hline Long & 42 & & & 36 & & 64 & & \\
\hline \multicolumn{9}{|l|}{ Lift burden at work } \\
\hline Low & 56 & & & 74 & & 103 & & \\
\hline High & 44 & & & 63 & & 71 & & \\
\hline
\end{tabular}

a 39 out of 108 blue-collar workers.

b 44 out of 153 blue-collar workers.

c 53 out of 178 blue-collar workers. $\mathrm{kg} / \mathrm{m}^{2}$ and average age was $46.0(\mathrm{SD} 9.0$ ) years, $31 \%$ were smokers and $27 \%$ reported high LBPi.

The average daily duration of forward bending was 41 (SD 32) minutes during work and 33 (SD 19) minutes during leisure time. The descriptive characteristics of workers with high LBPi compared with workers having low LBPi were similar (table 1). No significant associations between social support and the dichotomous variable of LBPi or the continuous LBPi variable $(\mathrm{F}=0.33)$ were observed. The descriptive characteristics did not reveal any noticeable differences for workers having long compared with short-moderate duration forward bending during work (table 3 ). Neither the crude nor the fully adjusted models showed any significant associations between forward bending during work and LBPi (table 4). The additional analyses on the association between forward bending and LBPi categorized into no LBP (score 0) and LBP (score 1-10) overall showed similar estimates as the main analyses (data not shown).

Furthermore, the sensitivity analyses using percentage of time spent forward bending during work showed very similar associations with LBPi as observed in the main analysis (data not shown). Accordingly, the sensitivity analyses using different cut-points for low and high LBPi (ie, $\leq 4$ and $\leq 6$ on the $0-10$ scale) resulted in very similar estimates as observed in the main analysis (data not shown).

\section{Effect modification by social support}

Workers with low level of social support and long duration of forward bending had higher likelihood of high LBPi (OR 2.97, 95\% CI 1.11-7.95) compared to workers with high level of social support and long duration of forward bending (table 5). Among workers with low social support, workers with long duration of forward bending had higher likelihood of high LBPi (OR 3.28, 95\% CI 0.99-10.90) compared to workers with shortmoderate duration of forward bending. Within the stratum of workers with high social support, workers with long duration of forward bending during work showed reduced likelihood of high LBPi (OR 0.39, 95\% CI 0.16-0.95) compared to workers with short-moderate duration of forward bending. The interaction analyses showed a significant interaction between forward bending during work, social support, and LBPi.

The analyses for effect modification by social support using the categorization of LBPi into no LBP (score 0 ) and LBP (score 1-10) revealed a similar increased OR for LBPi in the group with long duration of forward bending and low level of social support (OR 3.35, 95\% CI 1.26-8.90) referencing the group with long forward bending duration and high level of social support as found for the main effect modification analyses. 


\section{Discussion}

This study showed no statistically significant association between duration of forward bending of the trunk and LBPi in this cohort based on objective measurements among blue-collar workers. In line with our hypothesis, social support modified the relationship between forward bending of the trunk and LBPi. For example, workers experiencing low social support and having a long duration of forward bending during work were almost three times as likely to have high LBPi, compared to workers with high level of social support and long duration of forward bending.

Table 3. Descriptive characteristics of the blue-collar workers $(\mathrm{N}=457)$ stratified by short-moderate and long duration category of $\geq 30^{\circ}$ forward bending of the trunk while standing still or moving slightly during work. [SD=standard deviation.]

\begin{tabular}{|c|c|c|c|c|c|}
\hline \multirow[t]{3}{*}{ Variables } & \multicolumn{5}{|c|}{ Low-back pain intensity } \\
\hline & \multicolumn{2}{|c|}{$\operatorname{Low}(\leq 5)$} & \multicolumn{3}{|c|}{ High $(>5)$} \\
\hline & $\mathrm{N}$ Mean & SD & $\mathrm{N}$ & Mean & SD \\
\hline Population & 315 & & 142 & & \\
\hline $\begin{array}{l}\text { Mean per day of forward bending of } \\
\text { the trunk (min) }\end{array}$ & $315 \quad 26$ & 12 & 142 & 76 & 36 \\
\hline \multicolumn{6}{|l|}{ Gender } \\
\hline Male & 178 & & 47 & & \\
\hline Female & 137 & & 95 & & \\
\hline Age (years) & 31545.4 & 8.7 & 142 & 47.3 & 9.5 \\
\hline Smokers & $85^{a}$ & & 51 & & \\
\hline Seniority (months) & 293152 & 118 & 135 & 133 & 110 \\
\hline $\mathrm{BMI}\left(\mathrm{kg} / \mathrm{m}^{2}\right)$ & 31027.9 & 4.9 & 140 & 26.6 & 5.0 \\
\hline \multicolumn{6}{|l|}{ Low back pain intensity $(0-10)$} \\
\hline $\operatorname{Low}(\leq 5)$ & 226 & & 108 & & \\
\hline High $(>5)$ & 89 & & 34 & & \\
\hline \multicolumn{6}{|l|}{ Lift burden at work } \\
\hline Low & 146 & & 87 & & \\
\hline High & 136 & & 42 & & \\
\hline \multicolumn{6}{|l|}{ Social Support } \\
\hline Low & 70 & & 42 & & \\
\hline Moderate & 121 & & 36 & & \\
\hline High & 124 & & 64 & & \\
\hline
\end{tabular}

a 85 out of 301 blue-collar workers.

b 51 out of 138 blue-collar workers.

Table 4. Logistic regressions between duration of $\geq 30^{\circ}$ of forward bending of the trunk during work and high low-back pain intensity (LBPi $>5$ on a scale from 0-10) among blue-collar workers. [OR=odds ratio; $95 \% \mathrm{Cl}=95 \%$ confidence interval.]

\begin{tabular}{|c|c|c|c|c|c|}
\hline \multirow[t]{4}{*}{$\begin{array}{l}\text { Logistic } \\
\text { regressions }\end{array}$} & \multicolumn{5}{|c|}{$\begin{array}{l}\text { Duration category of } \geq 30^{\circ} \text { forward } \\
\text { bending of the trunk }\end{array}$} \\
\hline & \multirow[b]{3}{*}{$\mathrm{N}$} & Shor & derate & \multicolumn{2}{|c|}{ Long } \\
\hline & & \multicolumn{4}{|c|}{ High LBPi } \\
\hline & & $\mathrm{OR}$ & $95 \% \mathrm{Cl}$ & $\mathrm{OR}$ & $95 \% \mathrm{Cl}$ \\
\hline Crude & 457 & 1.0 & & 0.80 & $0.51-1.26$ \\
\hline Fully adjusted ${ }^{a}$ & 374 & 1.0 & & 0.79 & $0.45-1.37$ \\
\hline
\end{tabular}

a Adjusted for age, gender, seniority, BMI, smoking, the lift burden at work, social support as well as forward bending during leisure time.
Forward bending, low back pain, and social support

The lack of association between forward bending and LBPi was evident both in the crude analyses and when taking individual, lifestyle, and work-related risk factors into account. The additional analyses on the association between forward bending and LBPi categorized into no LBP (score 0) and LBP (score 1-10) supported this finding. This study therefore contradicts the general assumption that forward bending is a major work-related risk factor for LBP $(11,41)$. For example, a systematic review reported a moderate-to-strong relationship between forward bending during work and severe LBP (11), and forward bending for $\geq 2$ hours every day during work was strongly associated with LBP in a recent prospective study (47). However, a recent review from the Swedish Council on Health Technology Assessment pointed out that there are conflicting results regarding the association between forward bending and LBP (28, 48). These conflicting results might be explained by the different cut-points used to dichotomize LBPi. However, the sensitivity analyses of our study using different cutpoints for low and high LBPi (ie, $\leq 4$ and $\leq 6$ on the $0-10$ scale) showed overall similar estimates as for the main analyses, as did applying the categorization of LBP into no LBP (score 0 ) and LBP (score 1-10). However, future studies should consider specifically investigating if there are cut-points for the risk of LBP from both determinants and effect modifiers. The cut-point of $\leq 5$ and $>5$ of LBPi was chosen in this study due to its clinical relevance in workers' risk for sickness absence (34).

The current study confirmed our previous findings, that there is no cross-sectional association between forward bending and LBPi among blue-collar workers in Denmark (23). Using objective measurements, our studies constitute an important contribution to the investigation of the association between work-related forward bending and LBPi because previous studies have mainly relied on self-reported measures (11). Furthermore, this study is - to our knowledge - among the first using long-term objective measurements of forward bending during longer time periods, circumventing drawbacks due to selected time windows and short recording periods (18-21).

Another important finding of this study was the observation that social support modified the association between forward bending and LBPi. Workers with the combination of long duration of forward bending and low level of social support had almost three times higher OR for high LBPi compared to workers with long duration of forward bending and high level of social support (table 5). This finding remained in the additional analyses using a different cut-point for LBPi [no LBP (score 0) versus LBP (score 1-10)].

A general concern of investigations of the psychosocial work environment and LBP is common method bias 
Table 5. Effect modification of the duration of $\geq 30^{\circ}$ forward bending of the trunk while standing still or moving slightly during work on the level of low-back pain intensity (low LBPi $\leq 5$ and high LBPi $>5$ on scale from $0-10$ ) by social support (low, moderate and high) among blue-collar workers. [OR=0dds ratio; $95 \% \mathrm{Cl}=95 \%$ confidence interval.]

\begin{tabular}{|c|c|c|c|c|c|c|c|c|c|c|}
\hline \multirow[b]{4}{*}{$\begin{array}{l}\text { Level of social } \\
\text { support }\end{array}$} & \multicolumn{8}{|c|}{ Duration category of $\geq 30^{\circ}$ forward bending of the trunk } & \multirow{2}{*}{\multicolumn{2}{|c|}{$\begin{array}{l}\text { Long duration forward } \\
\text { bending within strata of } \\
\text { social support }\end{array}$}} \\
\hline & \multicolumn{4}{|c|}{ Short-moderate } & \multicolumn{4}{|c|}{ Long } & & \\
\hline & \multicolumn{4}{|c|}{ LBPi } & \multicolumn{4}{|c|}{ LBPi } & \multicolumn{2}{|c|}{ LBPi } \\
\hline & Low (N) & High (N) & $\mathrm{OR}{ }^{\mathrm{a}}$ & $95 \% \mathrm{Cl}$ & Low (N) & High (N) & $\mathrm{OR}{ }^{\mathrm{a}}$ & $95 \% \mathrm{Cl}$ & $\mathrm{OR}{ }^{\mathrm{a}}$ & $95 \% \mathrm{Cl}$ \\
\hline Low & 48 & 12 & 1.08 & $0.42-2.79$ & 20 & 14 & $2.97^{b}$ & $1.11-7.95$ & $3.28^{b}$ & $0.99-10.90$ \\
\hline Moderate & 69 & 25 & 1.51 & $0.65-3.48$ & 26 & 4 & 0.63 & $0.18-2.23$ & 0.53 & $0.16-1.78$ \\
\hline High & 68 & 32 & 1.95 & $0.86-4.41$ & 45 & 11 & 1.0 & & $0.39^{b}$ & $0.16-0.95$ \\
\hline
\end{tabular}

a $\mathrm{OR}$ adjusted for age, gender, seniority, BMI, smoking, the lift burden at work as well as forward bending during leisure time.

b Significant $(\mathrm{P} \leq 0.05)$.

(49), in which the reporting rate of LBP is shown to be affected by the psychosocial work environment, such as low job satisfaction and other unsatisfactory aspects of work (49). However, this concern does not seem to be the case in this study because no significant associations between social support and LBPi could be found.

Other plausible explanations for our findings may be that social support from colleagues and managers can influence the workers' needs and resources in a manner that facilitate tailoring of the work tasks to the pain state of the worker (28). This may entail that the worker's influence on how (but not how much) forward bending is performed may be lower among workers with a low level of social support compared to those with higher levels of social support. For example, workers with higher levels of social support may perform forward bending in a manner inducing lower risk for LBP, such as having fewer long lasting uninterrupted periods of forward bending, taking breaks and rest to ensure restitution, and having a greater opportunity for variation in work tasks, compared to workers with a low level of social support. Future studies should explore the potential mechanisms between forward bending of the trunk and LBP, for example by using methods for investigating time patterns of trunk movement (eg, exposure variation analyses) among workers with different levels of social support (50).

\section{Strengths and limitations}

In this study we followed a data protocol based on our previous study (23), but this time we introduced a large sample size allowing for stratified and sub-population analyses with a statistical power that enabled adjustment for possible confounders and effect modification (29).

We have measured the duration of workers' forward bending over several days continuously during both working and leisure hours, leaving other important aspects of the mechanical exposure, such as range of motion (51) and frequency of forward bending (52), unaddressed. This entails that our findings must be inter- preted with care. One method of studying the aspects of range and frequency of ergonomic exposures like forward bending of the trunk is exposure variation analysis (EVA). EVA enables to capture the exposure variation pattern of forward bending, containing information on changes over time (53), including frequency (54), the extent of the changes (55) as well as capturing uniformity of exposure sequences (56). Implementing EVA is out of the scope for this study, but it would be of interest to implement in future studies. However, practitioners working in the occupational safety and health field often use indicators of amount of time forward bending during work to estimate exposure and risk of LBP, and therefore the impact of time duration as such is likely to be easily applicable to practitioners work. Other important factors to consider when assessing physical risk factors of LBP are occupational pushing, pulling, lifting and twisting $(11,57)$. Since these aspects can affect the association between forward bending and LBP, we included self-reports of occupational lift burden as confounding variables in the analyses. Factors like muscle pain tend to bias self-reported measures of physical work demands $(16,17)$, since workers having pain can overestimate the physical exposures, thus leading to erroneous interpretations of associations between physical exposure and pain (23). However, obtaining valid diurnal objective measures of lifting and pulling for several consecutive days in a cohort of this size is, to the authors' knowledge, not yet feasible, leaving only self-reported measures available. It is a limitation of this study that we only use objective measures of the duration of forward bending of $\geq 30^{\circ}$. Further, we adjusted for the occupational lifting burden using self-reported measures. The interpretations of our findings should be made in light of lacking information regarding frequency and effect of the many other exposure variables that relate to forward bending.

Finally, self-reported questions on psychosocial work factors and health outcomes were used, which can be considered a limitation. Subjective measures of psychosocial factors at work increase the probability of false positive findings, that is workers experiencing 
problems are more likely to report certain psychosocial exposures than healthy workers (58). For example, if a worker experiences a low level of social support at work, this may induce a higher pain report compared to workers experiencing high levels of social support. This is a common source bias in cross-sectional studies with self-reported health outcomes, introducing risk of differential misclassification, and in this case an over estimation of the true modifying effect of social support. This is particularly an issue when measuring exposures and outcomes simultaneously (59). However, our data did not show any association between levels of social support and reporting of LBPi.

Social support at work in this study covered two aspects: social support among colleagues and from supervisors to employees (43). A frequently used questionnaire for addressing social support at work from colleagues and supervisors is the second version of the Copenhagen Psychosocial Questionnaire (COPsOQ II) where several questions are used to determine social support from supervisors as well as colleagues (43). In this study, two questions were used in agreement with Torp et al (27). Choosing solely two questions to establish social support may impact the accuracy and precision of the variable of social support. However, due to the comprehensive amount of questions in the DPhacto study [addressing several issues such as sociodemographic measures, lifestyle and health, musculoskeletal disorders, musculoskeletal pain-related sickness absence, productivity loss, work ability as well as perceived physical exertion during work (29)], a balance between precision of the inquired variables and the response burden on the participants was needed. Thus, this general trade-off was an inevitable limitation (43) that we acknowledge. Since the two applied questions do not provide a comprehensive measure of social support, we suggest future studies investigate the interactions between forward bending, social support, and LBP by using a full-scale questionnaire battery of social support. Finally, one should note that due to the cross-sectional study design, we cannot establish a causal relationship between forward bending and LBPi. However, prospective follow-up on frequent pain measures would be of interest.

\section{Concluding remarks}

This study indicates that there is no cross-sectional association between forward bending and LBPi in a general population of blue-collar workers in Denmark. However, social support modified the association between objectively measured forward bending and LBPi among bluecollar workers. Workers with long duration of forward bending during work and low social support were almost three times as likely to report high LBPi compared to workers with long duration of forward bending and high social support. Social support may therefore play a role in the association between duration of forward bending and LBP.

\section{Acknowledgements}

This study was conducted partly with financial support from the special pool targeted for the social area. We would like to thank the people involved in the preparation of the data collection, the actual data collection and the processing of data in the DPhacto.

\section{References}

1. Walker BF. The prevalence of low back pain: a systematic review of the literature from 1966 to 1998 . J. Spinal Disord. 2000;13(3):205-17. http://dx.doi.org/10.1097/00002517200006000-00003

2. Thiese MS, Hegmann KT, Wood EM, Garg A, Moore JS, Kapellusch J, et al. Prevalence of low back pain by anatomic location and intensity in an occupational population. BMC Musculoskelet Disord. 2014;15:283. http://dx.doi. org/10.1186/1471-2474-15-283

3. Andersson GB. Epidemiological features of chronic low-back pain. Lancet. 1999 Aug 14;354(9178):581-5. http://dx.doi.org/10.1016/S0140-6736(99)01312-4

4. Sterud T, Tynes T. Work-related psychosocial and mechanical risk factors for low back pain: a 3-year follow-up study of the general working population in Norway. Occup Environ Med. 2013;70(5):296-302. http://dx.doi.org/10.1136/ oemed-2012-101116

5. Katz JN. Lumbar disc disorders and low-back pain: Socioeconomic factors and consequences. J Bone Jt Surg. 2006 Jan;88:21-4. http://dx.doi.org/10.2106/JBJS.E.01273

6. Mehra M, Hill K, Nicholl D, Schadrack J. The burden of chronic low back pain with and without a neuropathic component: a healthcare resource use and cost analysis. J Med Econ. 2012;15(2):245-52. http://dx.doi.org/10.3111/136969 98.2011 .642090

7. Bongers PM, de Winter CR, Kompier MA, Hildebrandt VH. Psychosocial factors at work and musculoskeletal disease. Scand J Work Environ Health. 1993;19(5):297-312. http:// dx.doi.org/10.5271/sjweh. 1470

8. Murtezani A, Hundozi H, Orovcanec N, Berisha M, Meka V. Low back pain predict sickness absence among power plant workers. Indian J. Occup. Environ. Med. 2010 Aug;14(2):49 53. http://dx.doi.org/10.4103/0019-5278.72241

9. Yildirim Y, Gunay S, Karadibak D. Identifying factors associated with low back pain among employees working at a package producing industry. J Back Musculoskelet Rehabil. 2014;27(1):25-32. http://dx.doi.org/10.3233/BMR-130415. 
10. Thorbjornsson CO, Alfredsson L, Fredriksson K, Koster M, Michelsen H, Vingard E, et al. Psychosocial and physical risk factors associated with low back pain: a 24 year follow up among women and men in a broad range of occupations. Occup Environ Med. 1998;55(2):84-90. http://dx.doi.org/10.1136/oem.55.2.84

11. Wai EK, Roffey DM, Bishop P, Kwon BK, Dagenais S. Causal assessment of occupational bending or twisting and low back pain: results of a systematic review. Spine J. Elsevier Inc; 2010;10(1):76-88. http://dx.doi.org/10.1016/j. spinee.2009.06.005

12. Coenen P, Kingma I, Boot CR, Twisk JW, Bongers PM, van Dieen JH. Cumulative low back load at work as a risk factor of low back pain: a prospective cohort study. J Occup Rehabil. 2013;23(1):11-8. http://dx.doi.org/10.1007/s10926-0129375-Z

13. Kumar S. Cumulative load as a risk factor for back pain. Spine. 1990;15(12):1311-6. http://dx.doi.org/10.1097/00007632199012000-00014

14. Norman R, Wells R, Neumann P, Frank J, Shannon H, Kerr M A comparison of peak vs cumulative physical work exposure risk factors for the reporting of low back pain in the automotive industry. Clin Biomech. 1998;13(8):561-73. http://dx.doi. org/10.1016/S0268-0033(98)00020-5

15. Coenen P, Mathiassen SE, Kingma I, Boot CR, Bongers PM, van Dieen JH. The effect of the presence and characteristics of an outlying group on exposure-outcome associations. Scand J Work Environ Health. 2014. http://dx.doi.org/10.5271/ sjweh.3461

16. Kwak L, Proper KI, Hagströmer M, Sjöström M. The repeatability and validity of questionnaires assessing occupational physical activity - a systematic review. Scand J Work Environ Health. 2011;37(1):6-29. http://dx.doi. org/10.5271/sjweh.3085

17. Mikkelsen S, Vilstrup I, Lassen CF, Kryger AI, Thomsen $\mathrm{JF}$, Andersen JH. Validity of questionnaire self-reports on computer, mouse and keyboard usage during a four-week period. Occup Environ Med. 2007 Jan;64(8):541-7. http:// dx.doi.org/10.1136/oem.2005.026351

18. Andersen JH, Kaergaard A, Mikkelsen S, Jensen UF, Frost $\mathrm{P}$, Bonde JP, et al. Risk factors in the onset of neck/shoulder pain in a prospective study of workers in industrial and service companies. Occup Environ Med. 2003;60(9):649-54. http:// dx.doi.org/10.1136/oem.60.9.649

19. Thomsen JF, Mikkelsen S, Andersen JH, Fallentin N, Loft IP, Frost $\mathrm{P}$, et al. Risk factors for hand-wrist disorders in repetitive work. Occup Environ Med. 2007;64(8):527-33. http://dx.doi. org/10.1136/oem.2005.021170

20. Kerr MS, Frank JW, Shannon HS, Norman RW, Wells RP, Neumann WP, et al. Biomechanical and psychosocial risk factors for low back pain at work. Am J Public Health. 2001;91(7):1069-75. http://dx.doi.org/10.2105/ AJPH.91.7.1069

21. Hoogendoorn WE, Bongers PM, De Vet HCW, Ariens GAM, van Mechelen W, Bouter LM. High physical work load and low job satisfaction increase the risk of sickness absence due to low back pain: results of a prospective cohort study. Occup Environ Med. 2002;59(5):323-8. http://dx.doi.org/10.1136/ oem.59.5.323

22. Trask C, Mathiassen SE, Wahlstrom J, Forsman M. Costefficient assessment of biomechanical exposure in occupational groups, exemplified by posture observation and inclinometry. Scand J Work Environ Health. 2014;40(3):252-65. http:// dx.doi.org/10.5271/sjweh.3416

23. Villumsen M, Samani A, Jørgensen MB, Gupta N, Madeleine P, Holtermann A. Are forward bending of the trunk and low back pain associated among Danish blue-collar workers? A cross-sectional field study based on objective measures. Ergonomics. 2015;58(2):246-58. http://dx.doi.org/10.1080/ 00140139.2014 .969783

24. Thomas JS, France CR. The relationship between pain-related fear and lumbar flexion during natural recovery from low back pain. Eur Spine J. 2008;17(1):97-103. http://dx.doi. org/10.1007/s00586-007-0532-6

25. Fritz JM, George SZ. Identifying psychosocial variables in patients with acute work-related low back pain: the importance of fear-avoidance beliefs. Phys Ther. 2002;82(10):973-83.

26. Tims M, Bakker AB, Derks D. The impact of job crafting on job demands, job resources, and well-being. J Occup Health Psychol. 2013;18(2):230-40. http://dx.doi.org/10.1037/ a0032141

27. Torp S, Gudbergsson SB, Dahl AA, Fossa SD, Flotten T. Social support at work and work changes among cancer survivors in Norway. Scand J Public Health. 2011 Mar 7;39(6 Suppl):33-42. http://dx.doi.org/10.1177/1403494810395827

28. Lundberg U. Work conditions and back pain problems. Stress Health. 2015;31(1):1-4. http://dx.doi.org/10.1002/smi.2633

29. Jørgensen MB, Korshøj M, Lagersted-Olsen J, Villumsen M, Mortensen OS, Skotte J, et al. Physical activities at work and risk of musculoskeletal pain and its consequences: protocol for a study with objective field measures among blue-collar workers. BMC Musculoskelet. Disord. 2013;14:213. http:// dx.doi.org/10.1186/1471-2474-14-213

30. Vandenbroucke JP, von Elm E, Altman DG, Gotzsche PC, Mulrow CD, Pocock SJ, et al. Strengthening the Reporting of Observational Studies in Epidemiology (STROBE): explanation and elaboration. PLoS Med. 2007;4(10):e297. http://dx.doi.org/10.1371/journal.pmed.0040297

31. Skotte J, Korshøj M, Kristiansen J, Hanisch C, Holtermann A. Detection of Physical Activity Types Using Triaxial Accelerometers. J. Phys. Act. Health. 2014 Jan;11:76-84. http://dx.doi.org/10.1123/jpah.2011-0347

32. Korshøj M, Skotte JH, Christiansen CS, Mortensen P, Kristiansen J, Hanisch C, et al. Validity of the Acti4 software using ActiGraph GT3X+accelerometer for recording of arm and upper body inclination in simulated work tasks. Ergonomics. 2014;57(6):534-40. http://dx.doi.org/10.1080/ 00140139.2013 .869358

33. Kuorinka I, Jonsson B, Kilbom A. Standardised Nordic questionnaires for the analysis of musculoskeletal symptoms. 
Appl Ergon. 1987;18:233-7. http://dx.doi.org/10.1016/00036870(87)90010-X

34. Andersen LL, Clausen T, Burr H, Holtermann A. Threshold of musculoskeletal pain intensity for increased risk of longterm sickness absence among female healthcare workers in eldercare. PLoS One. 2012;7(7):e41287. http://dx.doi. org/10.1371/journal.pone.0041287

35. Hooftman WE, van Poppel MN, van der Beek AJ, Bongers PM, van Mechelen W. Gender differences in the relations between work-related physical and psychosocial risk factors and musculoskeletal complaints. Scand J Work Environ Health. 2004;30(4):261-78. http://dx.doi.org/10.5271/ sjweh.794

36. Burdorf A, Sorock G. Positive and negative evidence of risk factors for back disorders. Scand J Work Environ Health. 1997;23(4):243-56. http://dx.doi.org/10.5271/sjweh.217

37. Bjorck-van Dijken C, Fjellman-Wiklund A, Hildingsson C. Low back pain, lifestyle factors and physical activity: a population based-study. J Rehabil Med. 2008;40(10):864-9. http://dx.doi.org/10.2340/16501977-0273

38. Eatough EM, Way JD, Chang CH. Understanding the link between psychosocial work stressors and work-related musculoskeletal complaints. Appl. Ergon. Elsevier Ltd and The Ergonomics Society; 2012;43(3):554-63. http://dx.doi. org/10.1016/j.apergo.2011.08.009

39. Hartvigsen J, Lings S, Leboeuf-Yde C, Bakketeig L. Psychosocial factors at work in relation to low back pain and consequences of low back pain; a systematic, critical review of prospective cohort studies. Occup Environ Med. 2004;61(1):e2.

40. Linton SJ. Occupational psychological factors increase the risk for back pain: a systematic review. J Occup Rehabil. 2001;11(1):5366. http://dx.doi.org/10.1023/A:1016656225318

41. Jansen JP, Morgenstern H, Burdorf A. Dose-response relations between occupational exposures to physical and psychosocial factors and the risk of low back pain. Occup Environ Med. 2004;61(12):972-9. http://dx.doi.org/10.1136/ oem.2003.012245

42. da Costa BR, Vieira ER. Risk factors for work-related musculoskeletal pain: A systematic review of recent longitudinal studies. Am J Ind Med. 2010;(53):285-323. http://dx.doi.org/10.1002/ajim.20750

43. Pejtersen JH, Kristensen TS, Borg V, Bjorner JB. The second version of the Copenhagen Psychosocial Questionaire. Scand J Public Health. 2010;38:8-24. http://dx.doi. org/10.1177/1403494809349858

44. DJØF. Faktaark 8: Social kapital [Internet]. Djøfs undersøgelse af Psykisk Arbejdsmiljø, Stress og Balance 2012. [Fact sheet 8: Social Capital [Internet]. Djøf's study of Physiological Working Environment, Stress and Balance 2012]. 2014. https://www.djoef.dk/ /media/documents/djoef/f/faktaark nr 8 social kapital.ashx.

45. Holtermann A, Clausen T, Jørgensen MB, Burdorf A, Andersen LL. Patient handling and risk for developing persistent lowback pain among female healthcare workers. Scand J Work Environ Health. 2013;39(2):164-9. http://dx.doi.org/10.5271/ sjweh.3329.

46. Knol MJ, VanderWeele TJ. Recommendations for presenting analyses of effect modification and interaction. Int J Epidemiol. 2012 Apr;41(2):514-20. http://dx.doi.org/10.1093/ije/dyr218

47. Ramond-Roquin A, Bodin J, Serazin C, Parot-Schinkel E, Ha $\mathrm{C}$, Richard I, et al. Biomechanical constraints remain major risk factors for low back pain. Results from a prospective cohort study in French male employees. Spine; 2013; http:// dx.doi.org/10.1016/j.spinee.2013.05.040

48. SBU Yellow Report no 227. Occupational exposures and back disorders [Internet]. 2014. http://www.sbu.se/en.

49. Waddell G, Burton AK. Occupational health guidelines for the management of low back pain at work: evidence review. Occup Med. (Lond). 2001 Mar;51(2):124-35. http://dx.doi.org/10.1093/occmed/51.2.124

50. Samani A, Mathiassen SE, Madeleine P. Cluster-based exposure variation analysis. BMC Med Res Methodol. 2013;13:54. http://dx.doi.org/10.1186/1471-2288-13-54

51. Hoogendoorn WE, Bongers PM, de Vet HC, Douwes M, Koes $\mathrm{BW}$, Miedema MC, et al. Flexion and rotation of the trunk and lifting at work are risk factors for low back pain: results of a prospective cohort study. Spine. 2000;25(23):3087-92. http:// dx.doi.org/10.1097/00007632-200012010-00018

52. Solomonow M, Zhou BH, Baratta R V, Lu Y, Harris M. Biomechanics of increased exposure to lumbar injury caused by cyclic loading: Part 1. Loss of reflexive muscular stabilization. Spine. 1999;24(23):2426-34. http://dx.doi. org/10.1097/00007632-199912010-00003

53. Mathiassen SE. Diversity and variation in biomechanical exposure: What is it, and why would we like to know? Appl Ergon. 2006 Jul;37(4):419-27. http://dx.doi.org/10.1016/j. apergo.2006.04.006

54. Kilbom A, Persson J. Work technique and its consequences for musculoskeletal disorders. Ergonomics. 1987;30(2):273-9. http://dx.doi.org/10.1080/00140138708969706

55. Ciccarelli M, Straker L, Mathiassen SE, Pollock C. ITKids part II: variation of postures and muscle activity in children using different information and communication technologies. Work. 2011;38(4):413-27. http://dx.doi.org/10.3233/WOR-2011-1168.

56. Mathiassen SE, Moller T, Forsman M. Variability in mechanical exposure within and between individuals performing a highly constrained industrial work task. Ergonomics. 2003;46(8):800 24. http://dx.doi.org/10.1080/0014013031000090125

57. Riihimaki H. Low-back pain, its origin and risk indicators. Scand J Work Environ Health. 1991;17(2):81-90. http:// dx.doi.org/10.5271/sjweh. 1728

58. Madeleine P, Vangsgaard S, Hviid Andersen J, Ge HY, ArendtNielsen L. Computer work and self-reported variables on anthropometrics, computer usage, work ability, productivity, pain, and physical activity. BMC Musculoskelet Disord. 2013;14:226. http://dx.doi.org/10.1186/1471-2474-14-226

59. Solovieva S, Pensola T, Kausto J, Shiri R, Heliovaara M, Burdorf A, et al. Evaluation of the validity of job exposure matrix for psychosocial factors at work. PLoS One. 2014;9(9):e108987. http://dx.doi.org/10.1371/journal.pone.0108987

Received for publication: 8 June 2015 